\title{
TICKS
}

\section{GETTING TO KNOW YOUR TICKS}

TERRY D. GALLOWAY, Department of Entomology, Faculty of Agricultural and Food Sciences, University of Manitoba, Winnipeg, MB, R3T 2N2.

Terry_Galloway@umanitoba.ca

Figure 1. Male (left) and female (right) American dog ticks, Dermacentor variabilis. Note the distinct white markings on the scutum of each specimen. Terry Galloway

When I moved to Manitoba in 1973, everybody warned me about the cold winters and the hot summers. Many people warned me about the abundance of ferocious mosquitoes. Not one person, though, said anything about the wood ticks! Not one. My first encounter with ticks was on a trip to the field to collect mosquito larvae in May. I was rather amazed when we were returning to our truck and my companions started stripping down and removing ticks. I had only ever seen one tick, on a cat, in my 23 years in southern Ontario, and that was considered an extreme rarity at the time. But here we were just outside of Winnipeg, removing dozens of ticks from our own bodies. What kind of place was this?
Since then, I have had many opportunities to study ticks in Manitoba and to talk to people about ticks and tick lore. My first research experience was in 1979 and 1980 , with a graduate student who was particularly interested in the juvenile stages of the wood tick or American dog tick, Dermacentor variabilis (Say) (Burachynsky 1982; Burachynsky and Galloway 1985). Since that time, I have been involved with various tick survey activities in Manitoba, notably the surveys to determine the distribution and abundance of the blacklegged tick or deer tick, Ixodes scapularis Say, in Manitoba and Saskatchewan. In this article, I briefly describe many species of ticks on the prairies, and discuss the life cycles of some 
of the more commonly encountered species. Ticks are amazing animals, and I hope I can convince you to look at them in a slightly different light after you have read this account.

\section{Ticks on the Prairies}

There are 34 species of ticks recorded in Canada (Wilkinson 1979; Lindquist et al. 1999), of which at least 11 are known for the prairie region. There are other species, perhaps an additional four or five, that are currently unknown, but which may eventually be discovered in Canada, and there are many others which we see mainly as accidental introductions on birds, pets, domestic animals or humans, which are unlikely to become established here. For some insight into the potential for importation of exotic ticks, refer to Keirans and Durden (2001), who reported 99 species imported into the United States. The following is an account of some of the more frequently encountered hard ticks in the Canadian Prairies. There are species of soft ticks, also called argasid ticks, which are parasites of birds, bats and some rodents, but these are generally not common on the prairies and will not be considered here.

\section{Dermacentor spp.}

This genus includes three of the most conspicuous of all the ticks: $D$. variabilis (the wood tick, or American dog tick), $D$. andersoni Stiles (the Rocky Mountain wood tick), and D. albipictus (Packard) (the winter tick or moose tick). Paul Wilkinson has provided the most extensive discussion of these ticks in Canada. ${ }^{13}$ The adults of all three species are generally dark, reddish brown, and beautifully ornamented with white streaks and spots on their backs. Females, as in all species of hard ticks, have a platelike scutum that only partially covers the anterior region of the back, while the scutum in males extends all the way across the back. It is the scutum that bears the white markings, so it is easy to recognize at a glance whether you have found a male or female (Figure 1).
The American dog tick, D. variabilis, can be extremely abundant throughout southern Manitoba and southeastern Saskatchewan. There is evidence that this tick has gradually been increasing its range north and west in recent years. The adults are active from the time the snow disappears right through to early August, though the main peak in abundance is in May and June. Under favourable weather conditions, the adults rest in the grass and low shrubs waiting for a passing host, their front legs poised to latch onto hair or fabric. They do not jump, and they generally stay in low vegetation, not venturing into the overhead branches of trees. They will attach to a wide variety of host species, including foxes, coyotes, wolves, dogs, skunks, porcupines, racoons, cats, bears, badgers, deer, cattle, horses and humans. Females require several days to engorge fully with blood. At this time, males on the host seek out feeding females and mate with them. If you flip up a feeding female to expose her underside, you will often find a male or group of males. When a female has taken all the blood it can, it drops to the ground and seeks a sheltered spot to lay its eggs, of which there may be 1000-7000, laid over about three to six weeks. ${ }^{3}$ After all the eggs are laid, the female dies. Six-legged larvae hatch from the eggs and remain dormant in dense clusters in the leaf litter, where they will spend their first winter. In the spring, they crawl a short distance onto the surrounding vegetation, and attach to small rodents, especially voles, deer mice, jumping mice and chipmunks. When they are engorged with blood, they drop to the ground and moult to eight-legged nymphs. These nymphs actively seek a host during July and August, including the same species used by the larvae, to which they attach and feed to engorgement before dropping to the ground, where they moult to eight-legged adults. Most of these adults become dormant and spend the winter in the leaf litter, before becoming active in the spring and seeking their hosts. Just think, the majority of the adult wood ticks that we see in the spring would have begun their 
lives at least two years earlier. It is likely that these adults must find a host on which to feed, or they will die without surviving another winter.

The Rocky Mountain wood tick, $D$. andersoni, is found in western Canada, throughout south-central British Columbia, southern Alberta and east into southwestern Saskatchewan. The life cycle of this species is very similar to that of the American dog tick, except that the timing of the various stages is slightly different. When the larvae hatch from the eggs, they don't become dormant, but immediately begin to search for suitable hosts. Once they have acquired a bloodmeal, they drop to the ground and moult to the next stage, but in this case, it is the nymphs that become dormant and spend the winter. The nymphs become active in the following spring, and once fed, moult to adults. These adults become dormant and spend the winter in the litter on the ground. The adults become active early in the spring, feed on medium-sized to large hosts, including people.

The winter tick, D. albipictus, displays a completely different life cycle from its close relatives. The larvae become active in September and form dense aggregations on the vegetation, especially in areas where moose are abundant. Although they are most often associated with moose, they will also attach to deer, elk, cattle and horses. Humans, too, are sometimes infested, and I have dealt with calls from many anxious people who have found themselves covered by hundreds of tiny larval ticks. As the season advances, the larvae feed and moult to eight-legged nymphs, while still on the same host. After the nymphs have fed, usually from October to mid-February, they moult to the adult stage, but again remain on the same host animal. ${ }^{4}$ This tick can infest moose at extraordinary levels, frequently in the tens of thousands, ${ }^{11}$ and have tremendous impact on the health and well-being of the animal, especially where the range of moose may be restricted. They may even be responsible for the death of their host.

\section{Haemaphysalis spp.}

There are two species of Haemaphysalis that may be encountered in the Prairie region. Haemaphysalis leporis-palustris (Packard) is very common and abundant on rabbits and hares, especially in the ears. This small tick rarely attacks humans or domestic animals, but the juvenile stages may be occasionally found on birds. Haemaphysalis chordeilis (Packard) is a parasite of grouse, especially Sharp-tailed Grouse in parklands, and seems to be relatively host specific. Despite their host specificity, they require three different hosts to complete their life cycle.

\section{Ixodes spp.}

Ixodes is the genus with the greatest diversity of species in Canada, with at least seven possible species endemic to the Prairies. Fortunately, most parasitize only a small number of host species, and very seldom come into contact with humans or their pets. For example, Ixodes angustus Neumann and Ixodes muris Bishopp and Smith are mainly parasites of mice and voles, Ixodes sculptus Neumann and Ixodes kingi Bishopp mainly attack ground squirrels, Ixodes cookei Packard is usually found on woodchucks, and Ixodes banksi Bishopp typically parasitizes beavers.

There is one vagrant species of Ixodes that occurs in the Prairie Provinces, the blacklegged tick or deer tick, Ixodes scapularis Say. Although this species has gained notoriety due to its role as vector of the pathogen that causes Lyme Disease throughout much of eastern North America, there is no conclusive evidence that $I$. scapularis has become established and actually breeds in any of the Prairie Provinces. However, they are readily transported great distances by migrating birds, and since these vagrant ticks may have become infected with pathogens in their endemic homes, they have the potential to 
transmit those pathogens in regions quite far removed from the source. Infected ticks have been found in Manitoba, where 10\% to $15 \%$ carry the pathogen (Galloway et al. 2001). Since infected ticks are widely distributed but are not very frequently encountered, there is a small but persistent risk of infection in humans and their pets. The larvae and nymphs prefer to feed on small mammals, such as mice, voles and chipmunks, but they readily attach to birds, cats, dogs and humans. Adults of $I$. scapularis tend to feed on larger animals, including deer, dogs, cats and humans. In the Prairie Provinces, this species is most abundant in Manitoba, where it was first recorded in $1989,{ }^{5}$ then known as Ixodes dammini, but it has since been recorded in Saskatchewan, ${ }^{9}$ and in Alberta. ${ }^{12}$ For details on the life cycle of I. scapularis in Ontario, Lindsay et al. have published the most comprehensive account. One aspect of the life cycle of I. scapularis should be emphasized." Adults are the stage most frequently found on humans and pets in the Prairies, and this stage occurs most abundantly in the fall. In Manitoba, where over 200 I. scapularis have been collected during 1996 to 2001 (Lindsay and Galloway, unpublished), nearly all were adults, and the main peak of activity was September to November. Adult I. scapularis will remain active in the field until there is a good cover of snow on the ground. Adults that do not find a host in the fall will overwinter and resume their activity in the spring. Therefore, a second peak of adults occurs during April to June. Because people are so accustomed to finding wood ticks in the spring, they often fail to check themselves, their children and their pets when they have visited tick habitat in the fall.

\section{Rhipicephalus sanguineus (Latreille) and Amblyomma americanum Linnaeus}

The brown dog tick, $R$. rhipicephalus, and the lone star tick, $A$. americanum, are interesting ticks that aren't usually considered as part of the prairie tick fauna. In recent years, however, there are frequent records of the brown dog tick (Lindsay and Galloway, unpublished). This species is incapable of surviving our harsh prairie climate, but may readily become established in kennels and even in people's homes as a result of accidental introductions. The lone star tick is found in the southern United States, and will readily attach to humans and their pets. As people travel widely in the southern United States, they occasionally return with unwanted surprises, and it is always wise for travellers to check carefully for ticks whenever they have been hiking, camping or otherwise visiting suitable tick habitats.

\section{What to do when you find an attached tick}

Ticks are marvellously adapted ectoparasites that rely on blood to complete their development and to reproduce. Because they inhabit many of the same spaces that humans enjoy, we must learn to use a few common sense precautions.

1. If you are in tick-infested habitat, check yourself, your children and your pets carefully for ticks as soon as possible after visiting the location or as often as practical when in the field. If a tick is infected with a pathogen, the sooner it can be removed after it has attached, the less risk there is of transmission.

2. If you find an attached tick, don't panic. The lore of tick removal is extensive, and most of the elaborate means people employ to remove attached ticks are unnecessary. Ticks become attached by embedding their mouthparts into the skin. These mouthparts are armed with recurved teeth that anchor the tick to the host. There may even be salivary cement on the skin surface to attach the tick more firmly. The best method of tick removal is to grasp the tick as close to the skin surface as possible using tweezers, or your thumb and forefinger, and to pull the tick with slow, gradual effort until it comes away. It is not unusual for a small patch of tissue to adhere to the mouthparts. Some ticks, the Ixodes spp. for example, 
have much longer and more fragile mouthparts than the wood ticks. Consequently, the mouthparts are frequently broken when the tick is removed and may form a source of secondary infection.

3. It is important that you apply an antiseptic to the bite wound. Pay attention to where ticks have been attached, take note of any unusual reaction associated with tick bites, and report these to your physician or veterinarian as soon as possible.

4. If the tick in any way looks unusual to you, in either its size or colour, it is a good idea to save the specimen. If there are any questions about whether you have acquired a tick-borne pathogen from the bite of that particular tick, you can get the tick identified and perhaps even tested for the pathogen. The best way to keep a tick is to store it in an air-tight container in the freezer. Your local veterinarian can assist you in having the ticks identified by an appropriate laboratory.

\section{Acknowledgements}

Special thanks go to L. Robbin Lindsay, Canadian Science Centre for Human and Animal Health, Health Canada, Winnipeg, for his comments on the manuscript, and to Michael Alperyn, Department of Entomology, University of Manitoba for taking the photographs of the ticks.

1. BURACHYNSKY, V.I. 1982. A study of temporal and spatial relationships between small mammals and the immature stages (larvae and nymphs) of the American dog tick, Dermacentor variabilis (Say) (Acari: Ixodidae), in an aspen parkland region near Birds Hill Manitoba. M.Sc. thesis, University of Manitoba.

2. BURACHYNSKY, V.I. and T.D. GALLOWAY. 1985. Seasonal dynamics and distribution of American dog tick, Dermacentor variabilis (Say), larvae and nymphs at Birds Hill Park, Manitoba. Canadian Journal of Zoology 63:2748-2755.
3. CAMPBELL, A. and D.L. HARRIS. 1979. Reproduction of the American dog tick, Dermacentor variabilis, under laboratory and field conditions. Environmental Entomology 8: 734-739.

4. DREW, M.L. and W.M. SAMUEL. 1989. Instar development and disengagement rate of engorged female winter ticks, Dermacentor albipictus (Acari: Ixodidae), following single- and trickle-exposure of moose (Alces alces). Experimental \& Applied Acarology 6: 189-196.

5. GALLOWAY, T.D. 1989. Lyme Disease vector, Ixodes dammini, identified in Manitoba. Canadian Diseases Weekly Report 15-27: 85.

6. GALLOWAY, T.D., L. R. LINDSAY, A. DIBERNARDO and H. ARTSOB. 2001. Surveillance for blacklegged ticks, Ixodes scapularis (Acari: Ixodidae), in Manitoba, a non-endemic area of central Canada. Proceedings of the Northwest Conference on Diseases in Nature Communicable to Man, Winnipeg, Manitoba, 29 July-31 August, 2001.p.1.

7. KEIRANS, J.E. and L.A. DURDEN. 2001. Invasion: exotic ticks (Acari: Argasidae, Ixodidae) imported into the United States. A review and new records. Journal of Medical Entomology 38: 850861.

8. LINDQUIST, E.E., K.W. WU, and J.H REDNER. 1999 A new species of the tick genus Ixodes (Acari: Ixodidae) parasitic on mustelids (Mammalia: Carnivora) in Canada. The Canadian Entomologist 131: 151-170.

9. LINDSAY, L.R., H. ARTSOB, T.D. GALLOWAY and G. HORSMAN. 1999a. Vector of Lyme Borreliosis, Ixodes scapularis, identified in Saskatchewan. Canadian Communicable Diseases Report 25-9: 1-3. 
10. LINDSAY, L.R., S.W. MATHESON, I.K. BARKER, S.A. MCEWEN and G.A. SURGEONER. 1999b. Abundance of Ixodes scapularis (Acari: Ixodidae) larvae and nymphs in relation to host density and habitat on Long Point, Ontario. Journal of Medical Entomology 36: 243-254.

11. SAMUEL, W.M. and M.J. BARKER. 1979. The winter tick, Dermacentor albipictus (Packard, 1869), on moose, Alces alces, of central Alberta. In: Proceedings of the $15^{\text {th }}$ North American Moose Conference and Workshop 15: 303-348.

12. SCOTT, J.D., K. FERNANDO, S.N. BANERJEE, L.A. DURDEN, S.K. BYRNE,
M, BANERJEE, 'R.B. MANN, and M.G. MORSHAD. 2001. Birds disperse ixodid (Acari: Ixodidae) and Borrelia burgdorferiinfected ticks in Canada. Journal of Medical Entomology 38: 493-500.

13. WILKINSON, P.R. 1967. The distribution of Dermacentor ticks in Canada in relation to bioclimatic zones. Canadian Journal of Zoology 45: 517-537.

14. WILKINSON, P.R. 1979. Ixodides. In: Danks, H.V. (Ed.), Canada and its Insect Fauna. Memoirs of the Entomological Society of Canada, No. 108. pp. 265-267.

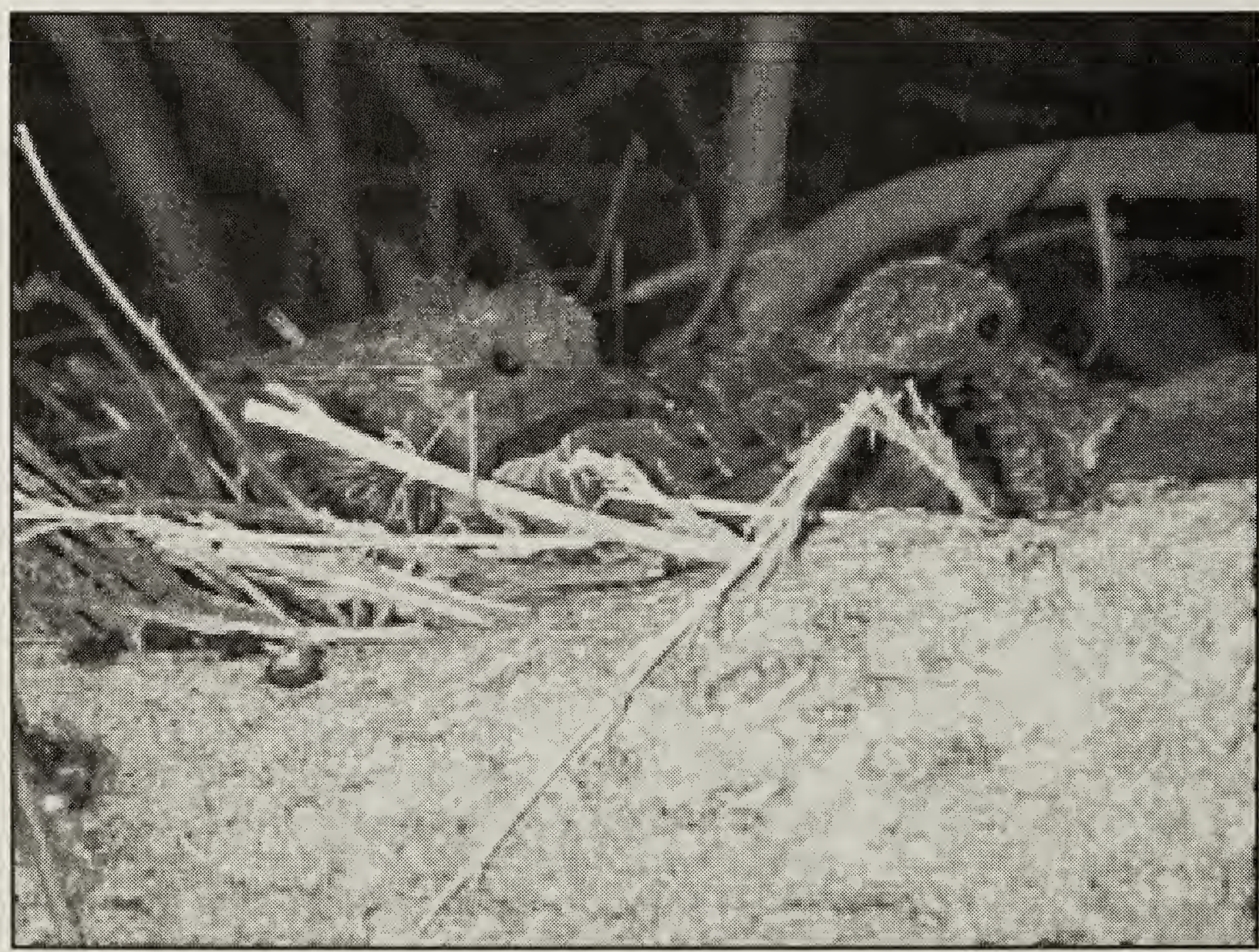

